\title{
Combined Heat and Power Plant Installation at Oil and Gas Fields: Is It Cost-Effective?
}

\author{
Zorana Božić $^{1 * *}$, Veselin Perović́ ${ }^{1}$, Branislav Nerandžić ${ }^{1}$, Slavka Nikolić ${ }^{1}$, Nikolaos Koltsaklis ${ }^{2}$, Nebojša \\ Vojvodić ${ }^{3}$
}

${ }^{1}$ Department of Industrial Engineering and Management, University of Novi Sad, Faculty of Technical Sciences, Novi Sad, Serbia. ${ }^{2}$ Department of Electrical and Computer Engineering, University of Western Macedonia, 50100 Kozani, Greece.

${ }^{3}$ NIS j.s.c Novi Sad, Novi Sad, Serbia.

\begin{abstract}
How to cite this paper: Zorana Božić, Veselin Perović, Branislav Nerandžić, Slavka Nikolić, Nikolaos Koltsaklis, Nebojša Vojvodić. (2021) Combined Heat and Power Plant Installation at Oil and Gas Fields: Is It Cost-Effective? Journal of Electrical Power \& Energy Systems, 5(1), 33-45.

DOI: 10.26855/jepes.2021.05.001
\end{abstract}

Received: March 22, 2021

Accepted: April 20, 2021

Published: May 11, 2021

*Corresponding author: Zorana Božić, Department of Industrial Engineering and Management, University of Novi Sad, Faculty of Technical Sciences, Novi Sad, Serbia.

Email: zoranabozic3@gmail.com

\begin{abstract}
The paper presents an economic feasibility analysis applied to assess the cost effectiveness of implementing a combined heat and power system at oil and gas fields. The purpose of this paper is to present a generic methodological framework by calculating return on investments in order to investigate the economic benefit and a payback period at the plants installed capacity. The findings of this analysis demonstrate that the mode of operation with sale of electricity at feed-in tariff and supply of excess heat to third parties is the most cost-effective because of its shortest payback period of 2.80 years. However, mode of operation with sale of electricity at free market and using heat for own consumption is the least economical, with payback period of 20.84 years. The paper provides important insights into strategic long-term and challenging decisions made by investors highlighting potential risks and providing the roadmap and appropriate price signals on critical energy projects under market conditions.
\end{abstract}

\section{Keywords}

Combined Heat and Power, Return on Investments

\section{Introduction}

Energy efficiency is evidently gaining prominence, becoming a topic of general interest, as it helps successfully combat climate changes. Extreme fluctuation of energy prices and rising risks associated with gas, oil and electricity supply represent an increasing economic challenge for the industry sector in the countries rich in intensive production processes.

Thermal power plants in the region are among the biggest polluters in Europe and the only question remaining is how to stimulate the substitution of these plants by new ones that produce electricity from renewable sources. Accordingly, capital projects related to energy efficiency increase, which are in fact combined heat and power plants (CHP), are contributing to energy production and they are expected to replace huge centralised systems in the near future [1]. To achieve this, an investment plan needs to be made and all associated costs reviewed, by envisaging the cash flow of such investment. The evaluation of the CHP plant, in order to be robust, has to capture uncertainties on endogenous parameters affecting its profitability. For the purpose of this paper, realistic inputs on gas production and all associated costs are considered, given by the technical documentation provided in NIS j.s.c. [2]. 


\section{Literature Review}

The Republic of Serbia's energy development strategy by 2030 involves 9\% saving on the current energy consumption [3]. However, Serbia is energy dependent on imports as $30 \%$ of its energy demand is met by purchasing from foreign markets, a reason sound enough to direct more investments into energy efficiency increase [4]. Development prospects lie in unconventional energy sources and Serbia is a great potential with its sources such as wind, solar and geothermal energy. The total renewable energy sources potential that is technologically available in the Republic of Serbia is estimated at 5.65 million tons of oil equivalent (toe) per year [5].

According to Rajović et al. [6], utilization of associated petroleum gas in combined heat and power units and heat boilers can lead to noticeable greenhouse gases mitigation and resource depletion avoidance. Colmenar-Santos et al. [7] highlight the significant cost and fuel savings that could be achieved by utilizing the waste heat from conventional power plants through district heating and cogeneration in the EU-28. Kang et al. [8] implemented an economic assessment of the CHP units' installation, examined the impacts of gas mixing, and heat sales ratio on their economic return. Sadeghian and Ardehali [9] presented an approach for the optimal scheduling of combined heat and power units along with conventional thermal power ones so as to maximize the economic profits and minimize the environmental impact of generation companies operating in a deregulated electricity market. Klaassen and Patel [10] presented a techno-economic assessment of the utilization of natural gas combined heat and power units in district heating evaluating the energy savings and the $\mathrm{CO}_{2}$ mitigation costs. Mojica et al. [11] developed an optimization framework to determine the optimal investment planning of a district energy system consisting of boilers or combined heat and power units providing heat and electricity. Amirnekooei et al. [12] developed an energy pricing optimization formulation of an integrated natural gas and electric power network taking into account a series of techno-economic constraints. Koltsaklis et al. [13] a mixed integer linear programming model in order to optimally determine the design and production scheduling of energy systems based on CHP units and taking also into account the existence of a possible external heat source.

The aforementioned studies explore the effects of technical, economic and environmental side of implementing CHP units. In this paper, the authors consider the interaction and interdependency of oil and gas fields with high-efficiency combined heat and power units. Namely, dissolved gas that is obtained as a by-product from the production of crude oil, often contains impurities that are difficult to extract without additional financial investments in technology for the preparation of gas. It is usually necessary to separate $\mathrm{CO}_{2}, \mathrm{~N}_{2}$, and at some locations $\mathrm{H}_{2} \mathrm{~S}$, which is extremely toxic to humans, but can also destroy the equipment's installation when it turns into sulphuric acid. Technological gas like this, is not possible to put into the trunk or distribution pipeline, instead it is burned in a flare. This process is environmental unfriendly due to large extent of air pollution. On the other hand, great economic losses are indicated. In order to reduce these two negative impacts, both economic and environmental, the solution is to implement cogeneration plants with gas engines, for production of electrical and thermal energy from dissolved gas. Accordingly, the application of these systems is reflected positively in terms of environmental protection and economic benefits.

The main contributions and the novel features characterizing this work include:

1) Methodological framework with data analytics approach investigates feasibility studies of 4 different CHP production scenarios, in order to examine the shortest payback period: sale of electricity at feed-in tariff with using heat for own consumption, sale of electricity at feed-in tariff with supply of heat to third parties, sale of electricity at free market with using heat for own consumption and sale of electricity at free market with supply of heat to third parties.

2) For the purpose of identifying decision-making criteria, sensitivity analysis is also included. This analysis examines the effect on Net present value (NPV) in the range from $-20 \%,-10 \%$, to $10 \%, 20 \%$, deviation of capital expenditure (CAPEX) and operational expenditure (OPEX), which helps the investor in decision-making process.

3) The proposed research conducts a general model for investment scope and its financial results of the companies with their own input energy. In order to provide a solution for potential investors which have to buy gas, an additional scenario is added with assumptions of the best cost-effective scenario and gas purchase.

4) Additional investigations have been implemented to examine the environmental performance of the proposed investment plan, in terms of $\mathrm{CO}_{2}$ emissions savings. 
The paper is organized as follows. Section 3 introduces the data and methodology description. Section 4 presents Case study description, while in Section 5 explains empirical results of econometric research and discussion. Section 6 provides relevant conclusions.

\section{Materials and Methods}

\subsection{Empirical data}

One of Serbian oil and gas fields produces crude oil and associated gas. Some of the gas produced is used in boilers for heat generation, while the remaining gas is flared. The installation of cogeneration module enables generation of heat to be used by the facility and the electricity produced is supplied to the grid operated by EPS ltd (Electric Power Industry of Serbia) at a subsidized price. Thus, small-sized power plants at oil and gas fields produce power and heat from gas which cannot be supplied to the public gas grid operator given the high content of inert gases, namely carbon dioxide and hydrogen. The vital part of the system is the chemical preparation of gas because the engine must be tailored to specific as properties on the location, which largely determines the system's functioning and the engine's longevity, because these systems are mostly designed to have a lifespan of 12 to 15 years [2].

Table 1. Calorific value of gas components

\begin{tabular}{|c|c|c|c|c|c|c|c|c|}
\hline Component & $\mathrm{C} 1$ & $\mathrm{C} 2$ & C3 & iC4 & nC4 & iC5 & nC5 & C6 \\
\hline Lower heating value $\mathrm{kJ} / \mathrm{Nm}^{3}$ & 33.900 & 60.400 & 86.400 & 112.400 & 112.000 & 138.000 & 133.800 & 164.400 \\
\hline
\end{tabular}

The starting point is the analysis of prospects to deliver dissolved gas at this field. Production in this field involves several reservoirs. Figure 1 shows dissolved gas production trends that are prepared based on oil output trends for the field reservoirs and based on the historical data for oil and dissolved gas production. Miners define gas production and geologists from NIS j.s.c., accordingly, data origins are internal reports. The gas output trends over the exploitation period of 15 years, was presented in Figure 1, are declining, and also suggests that the daily gas output largely daily gas demand in rator.

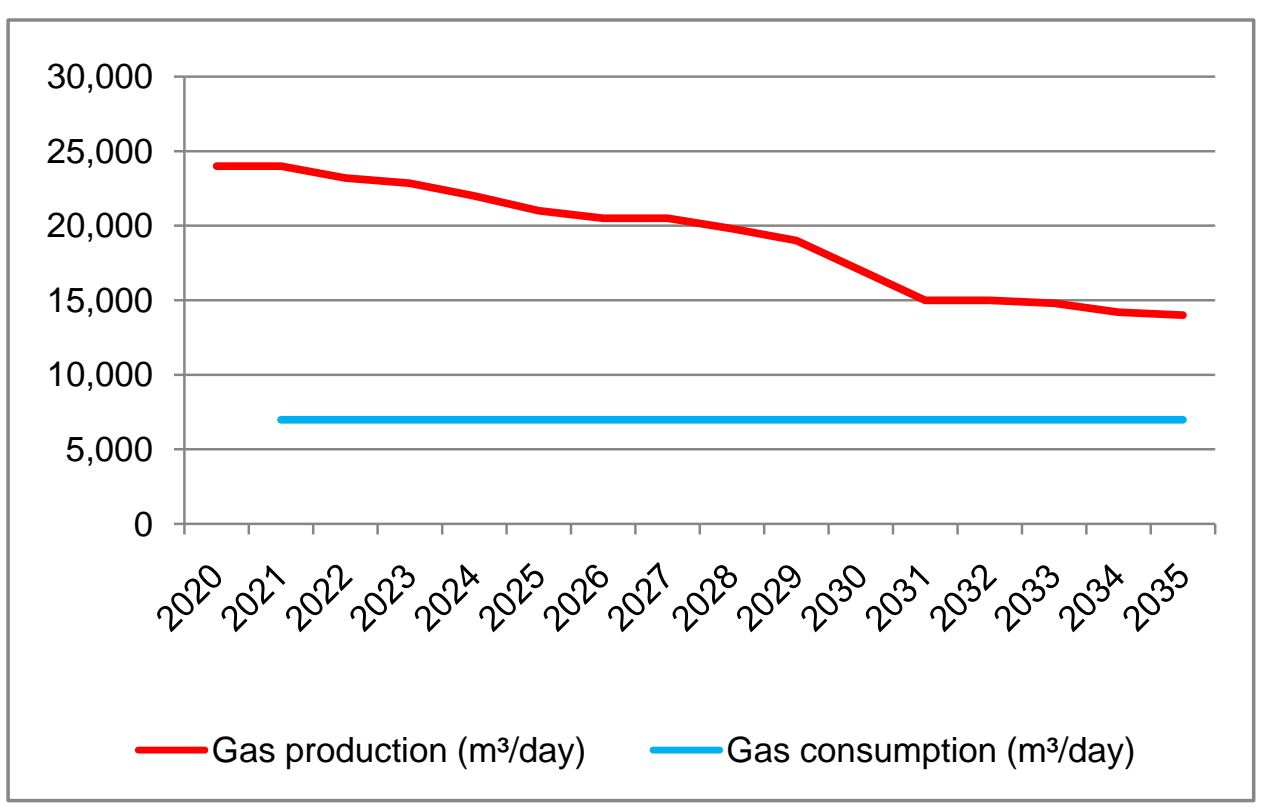
meets the consumption the cogene-

Figure 1. Daily gas output trends and daily gas consumption by cogenerator.

Table 2. Gas content at the gas field

\begin{tabular}{ccccccccccc}
\hline Component & $\mathrm{CH}_{4}$ & $\mathrm{C}_{2} \mathrm{H}_{6}$ & $\mathrm{C}_{3} \mathrm{H}_{8}$ & $\mathrm{iC}_{4} \mathrm{H}_{10}$ & $\mathrm{nC}_{4} \mathrm{H}_{10}$ & $\mathrm{iC}_{5} \mathrm{H}_{12}$ & $\mathrm{C}_{6} \mathrm{H}_{14}$ & $\mathrm{C}_{7} \mathrm{H}_{16}$ & $\mathrm{~N}_{2}$ & $\mathrm{CO}_{2}$ \\
\hline Mol (\%) & $82 ., 24$ & 3.9 & 0.46 & 0.08 & 0.04 & 0.02 & 0.06 & 0.04 & 3.64 & 9.58 \\
\hline
\end{tabular}


The gas quality data for the field provides information on the lower heating value of gas. Depending on the number of wells put in operation and also on their production changes, gas components listed in this part of the project may deviate $\pm 5 \%$ from the table data (see Table 1 ). Having determined the available gas quantities in $\mathrm{m}^{3}$ for the period of 15 years and its chemical composition (see Table 2), it is necessary to define the heat consumption at the site and limitations of the power system at grid connection point.

\subsection{Methodology framework}

In terms of methodology, this paper provides a general model for determining both technical and economical requirements in implementation of CHP.

\subsubsection{Technical parameters}

The lower heating value of gas corresponds to the share of gaseous hydrocarbons in the total gas compound content, and it is calculated with the following formula [1]:

$$
\mathrm{Hd}=\frac{\mathrm{C} 1 \cdot \mathrm{CH}_{4}+\mathrm{C} 2 \cdot \mathrm{C}_{2} \mathrm{H}_{6}+\mathrm{C} 3 \cdot \mathrm{C}_{3} \mathrm{H}_{8}+\mathrm{iC} 4 \cdot \mathrm{iC}_{4} \mathrm{H}_{10}+\mathrm{nC} 4 \cdot \mathrm{nC}_{4} \mathrm{H}_{10}+\mathrm{iC} 5 \cdot \mathrm{iC}_{5} \mathrm{H}_{12}+\mathrm{nC} 5 \cdot \mathrm{nC}_{5} \mathrm{H}_{12}+\mathrm{C} 6 \times \mathrm{C}_{6} \mathrm{H}_{14}}{100}
$$

Where: $\mathrm{Hd}$ - the lower heating value of gas, $\mathrm{C}_{1-6}$ - calorific value of gas components, $\mathrm{CH}$ - gas content at the gas field. Equation (1) has two values, in order to compare the data, lower heating value of gas can be expressed in $\mathrm{kJ} / \mathrm{Nm}^{3}$, and by converting the measurement units $\mathrm{J}=\mathrm{Ws}$, in $\mathrm{kWh} / \mathrm{m}^{3}$.

The plant's installed power is $1 \mathrm{MW}$ and gas consumption is determined on the basis of technical data on the degree of utilization (electricity or heat). While the total gas energy input equals:

$$
\mathrm{Ge}=\mathrm{V} \cdot \mathrm{Hd}
$$

Where: Ge — gas energy input, $\mathrm{V}$ - gas consumption, $\mathrm{Hd}$-lower heating value of gas. Equation (2) can be calculated in two more different ways. If the electricity utilization degree is 0.4 and the rated output power $1.000 \mathrm{~kW}$, by multiplying these values it is given an hourly energy that needs to be inserted into gas engine. The same result could be obtained from multiplication of thermal utilization degree and rated heat power. Note: electricity utilization degree is determined by an average value from technical documentation of the leading CHP manufactures. By analyzing the criteria in detail, the rated output power of $1.000 \mathrm{~kW}$ or $1.125 \mathrm{~kW}$ of rated heat power is determined. The given powers add up to $85 \%$ of the utilization rate of cogenerator capacities ( $40 \%$ electric power and $45 \%$ thermal power), as required by the Decree on Incentives for Privileged Power Producers [14].

Gas consumption can be obtained from the Figure 1, but calculation on daily basis is also available from the following formula:

$$
\mathrm{V}=\frac{\frac{P_{e l}}{\eta_{e l}}}{\mathrm{Hd}}
$$

Where: $\mathrm{V}$-gas consumption, $\mathrm{P}_{\mathrm{el}}$ —rated electrical power, $\eta_{\mathrm{el}}$-electrical coefficient of efficiency, Hd-lower heating value of gas. In addition, just as the Figure 1 shows a markedly higher production of gas than consumption, it is important to note that the field thus enables the installation of more than one module unit, as it is technically feasible to implement a plant with much higher rated output power at the grid connection point. Prerequisite to obtaining the status of preferential producer i.e. feed-in tariff is in fact using both types of energy (electrical and thermal) with a total share of $85 \%$.

\subsubsection{Economic parameters}

The starting point for determining the investment scope is compiling a specification of equipment and materials. These costs aggregate the following: technological equipment and machinery, construction and electrical equipment and materials, measurement materials and equipment, regulation and control, fire and gas detection and assembly works. There are also the costs of setup and commissioning and the costs of designing, documentation and connection to the grid.

Under the Decree on Incentives for Privileged Power Producers, regular annual correction of incentive purchase prices is made due to inflation in the Eurozone determined every February as follows:

$$
\mathrm{C}_{1}=\mathrm{C}_{0} \times\left(\frac{1+\mathrm{p}_{\text {inf }}}{100}\right)
$$


Where: $\mathrm{C}_{1}$ —new incentive purchase price, $\mathrm{C}_{0}$ - former incentive purchase price, $\mathrm{p}_{\text {inf }}$-annual Eurozone inflation published by EU authorities, expressed as percentage [14]. The Ministry in charge of finances establishes the annual Eurozone inflation, on request from the public supplier. For the purpose of this paper and to establish the feasibility of CHP, the authors have estimated rate of inflation at $1.5 \%$.

Free Cash Flow (FCF) is defined as cash flow in excess of required funding all projects that have positive net present values when discounted at the relevant cost of equity [15]. FCF to the company can be written as follows [16]:

$$
\text { FCF=FCE+FCD- } \tau \text { Int }
$$

Where: FCF-Free Cash Flow to the company, FCE—Free Cash Flow to equity, FCD—Free Cash Flow to debt holders, $\tau$ Int-interest-tax-shield benefits from the cash flow to debt holders. In this paper, Net Profit equals EBIT reduced by tax. The authors use Stewart's terminology in Equation (5) by referring to the restatement of income as net operating profit after taxes (NOPAT) [17]. Accordingly:

$$
\text { FCF }=\text { NOPAT }+d-\text { tni }
$$

Where: $\mathrm{d}$-depreciation and tni-total net investment. Net Present Value (NPV) of an investment project is the sum of the present values of its estimated incoming cash flows minus the present values of all estimated cash outlays [18]. If the initial cash flow in period $\mathrm{m}$ and final incremental cash flow in period $\mathrm{m}+\mathrm{M}$, with the $\Delta$ operator which represents the incremental impact of the project's acceptance on the components of FCF, then NPV equals [16]:

$$
\mathrm{NPV}=\left[\frac{1}{\omega_{\mathrm{m}}}\right] \sum_{\mathrm{t}=\mathrm{m}}^{\mathrm{m}+\mathrm{M}} \omega_{\mathrm{m}}(\Delta \mathrm{FCF})
$$

For the purpose of this paper, the sum of Discounted Cash Flow (dFCF) is used as valuation method for estimating the attractiveness of an investment opportunity, defined as the project's NPV, calculated as follows [18]:

$$
\mathrm{NPV}=\mathrm{FCF}_{0}+\frac{\mathrm{FCF}_{1}}{(1+\mathrm{r})^{1}}+\frac{\mathrm{FCF}_{2}}{(1+\mathrm{r})^{2}}+\cdots+\frac{\mathrm{FCF}_{\mathrm{n}}}{(1+\mathrm{r})^{\mathrm{n}}}
$$

Where: NPV—Net Present Value, FCF-Free Cash Flow, $r$ - discounted rate, $\mathrm{i}=1$, $n$ - number of the year for which the $\mathrm{dFCF}$ is calculated.

Internal rate of return (IRR) is the rate for which "at the end of project the sum of accumulated (discounted) values of all the inflows is balanced numerically by the sum of accumulated (discounted) values of all the outflows" [19]. Profitability Index (PI) is a tool which evaluates a proposed investment by using exact sum of invested capital, period when each increment of this capital must be expanded, and a yearly schedule of all anticipated cost, including taxes [20]. PI shows the relative profitability of any project, or the present value per euro of initial cost, and it can be calculated as follows [21]:

$$
\text { PI }=\frac{\text { Present value of future cash flows }}{\text { Initial cost }}
$$

In this paper the return on investment is calculated as summation of absolute value from quotient on the last year obtaining negative net present value with the first year in positive net present value, and ordinal number of the year in which project starts collecting the profit. If net present value equals to total revenues deducted by profit tax and annual depreciation, by applying discounted rate it can be determined the period in which the investment will be recouped. The authors here measure FCF by adding amount of depreciation to net profit, on yearly basis.

\section{Case Study Description}

The cogenerator's daily consumption of gas is $6.984 \mathrm{~m}^{3} / \mathrm{day}$, as it is shown in Figure 1, while the annual consumption is $2.328 .000 \mathrm{~m}^{3} /$ year. By replacing the values stated in Tables 1 and 2, the resulting lower heating value of gas is $\mathrm{Hd}=30,9 \mathrm{~kJ} / \mathrm{Nm}^{3}$, and by converting the measurement units $\mathrm{J}=\mathrm{Ws}$, the lower heating value of gas equals 8.58 $\mathrm{kWh} / \mathrm{m}^{3}$. Multiplying gas consumption on hourly basis of $291 \mathrm{~m}^{3} / \mathrm{h}$ with its lower heating value of $8.58 \mathrm{kWh} / \mathrm{m}^{3}$, the resulting input energy of gas equals $2.496,78 \mathrm{kWh}$, or rounded to cca $2.500 \mathrm{kWh}$. By applying the same unit for the plant's input consumption of gas in $\mathrm{m}^{3} / \mathrm{h}$ and the output unit of electricity and heat in $\mathrm{kWh}$ (so as to compare the data), the result is that production of $1.000 \mathrm{~kW}$ of electricity and $1.125 \mathrm{~kW}$ of heat (for 1 hour of operation) requires 
a total input gas energy of $2.500 \mathrm{kWh}$, representing also their efficiency rate of $40 \%$ for electricity and $45 \%$ for heat. Taking into account the plant's installed power of $1.000 \mathrm{~kW}$ and work hours per year $-8.000 \mathrm{~h} /$ year, multiplication of these values gives a gross electricity output of $8.000 .000 \mathrm{kWh}$. Power losses from the cogeneration output to the point of takeover are around $5 \%$, so a total of $7.600 .000 \mathrm{kWh} /$ year of net electricity output is fed into the distribution grid. The heat delivered to consumers on an annual basis amounts to $9.000 .000 \mathrm{kWh} / \mathrm{year}$.

The procedure for executing the license of access to the distribution system costs around $€ 2.000$ on average and is factored in the calculation of capital expenditure. The initial cost of investment with the capital expenses is $€$ 1.300.000 per installed power of $1 \mathrm{MW}$. Since this is a turnkey project, the CAPEX is calculated and determined by the producer. If depreciation is on an annual basis, for the period of 15 years the plant is depreciated in the amount of $€ 86.667$ a year. According to the technical specification of equipment manufacturers, capital overhaul is in the eight year of operation, namely after 64.000 work hours. The cost of capital overhaul is estimated at $€ 200.000$ and becomes due in the following year. In addition, of the total 8.760 hours per year, producers estimate that regular servicing and maintenance and other planned or unplanned shutdowns should take up 760 hours a year in total. This altogether leads to a result of $2.328 .000 \mathrm{~m}^{3} /$ year in total annual gas consumption. According to the specification determined by the producer, the cost of plant maintenance per hour of operation is roughly $€ 7$, amounting to $€$ 56.000 for 8.000 work hours a year. These costs cover nearly all the plant expenses until the end of its lifecycle and are related to installation maintenance, consumables, spare parts, engine oil change etc. Considering that cogeneration module is delivered so as to become a fully automated system displaying all parameters and trends for both inputs and outputs, there is no need to engage additional personnel to work at the plant. It is sufficient to re-train the current staff at the field to make simple reading of any anomaly on the control panel, alarmed by the system itself. In this respect, operating expenses include the total costs of maintenance amounting $€ 840.000$ and costs of capital overhaul of $€ 200.000$ for the period of 15 years.

\section{Results and Discussions}

This paper aims to demonstrate the economic feasibility of CHP taking into account four different scenarios and sensitivity analysis.

\subsection{Scenario 1-Sale of electricity at feed-in tariff with using heat for own consumption}

This scenario implies that net power output is fed into the distribution grid at the incentive price of $0.0955 € / \mathrm{kWh}$ [14], or $95.5 € / \mathrm{MWh}$ in 2021 . The present analysis applies the inflation rate of $1.5 \%$, which is cumulatively applied to the feed-in tariff increase, in accord with the foregoing Regulation. This mode of operation yields revenues through sale of electricity while heat is used for own consumption. By determining revenues and expenses based on input data and feed-in tariff data, the authors get information on the indicators presented in Figure 2 which shows that the invested money will be returned in a period of 3.62 years for the given mode of operation. Figure 2 also suggests a mild increase in net profit, with a decline segment in 2029 due to the costs of large capital overhaul. From the Project Sensitivity Analysis presented in Figure 3, it can be concluded that deviations in capital and operating expenses in the given percentage, do not weigh on the project's cost-effectiveness significantly.

\subsection{Scenario 2-Sale of electricity at feed-in tariff with supply of heat to third parties}

Supplying heat to third parties requires certain technical prerequisites to be met. If the plant is set to operate in such mode, the economic analysis needs to take into account the price of heat. Based on experience, a selling price of $0.03 € / \mathrm{kWh}$ of heat is adopted. This ensures additional revenue and shortens the return on investment period, which is 2.80 years, as shown in Figure 4. The price of thermal energy is given taking into account the price of electricity, due to the fact that both thermal and electrical production is expressed in $\mathrm{kWh}$. In order to be sure, the authors have adopted more than 30\% lower price per kWh of thermal energy. Sensitivity analysis depicted in Figure 5 represents small deviations, considering the total amount of NPV, which can have minor impact on the project's cost-effectiveness. 


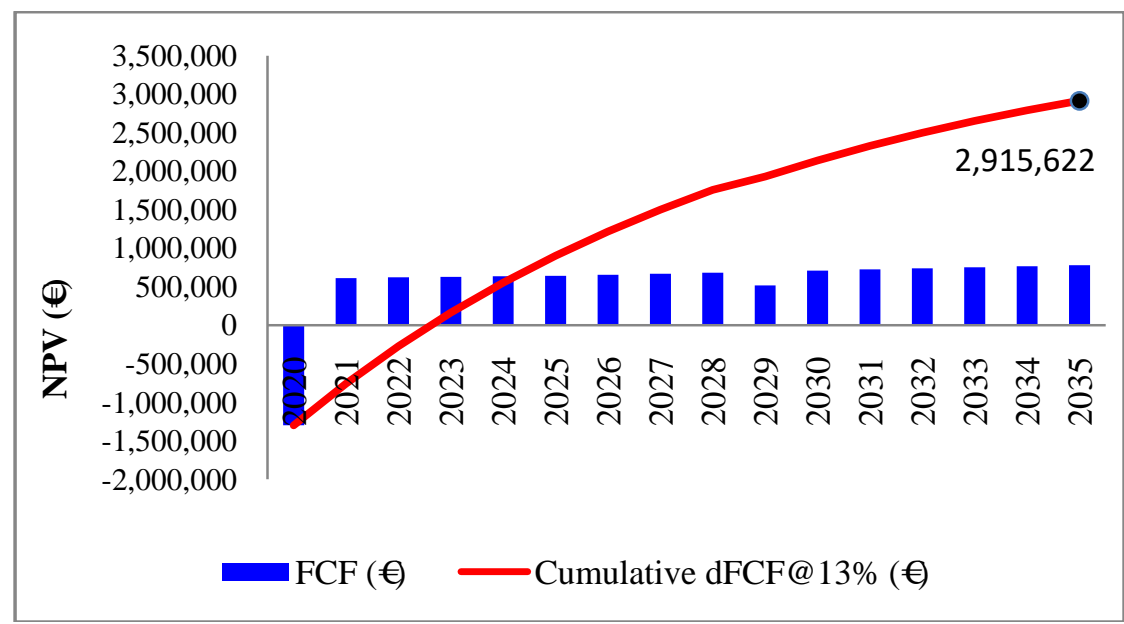

Figure 2. Review of cash flow trends for Scenario 1.

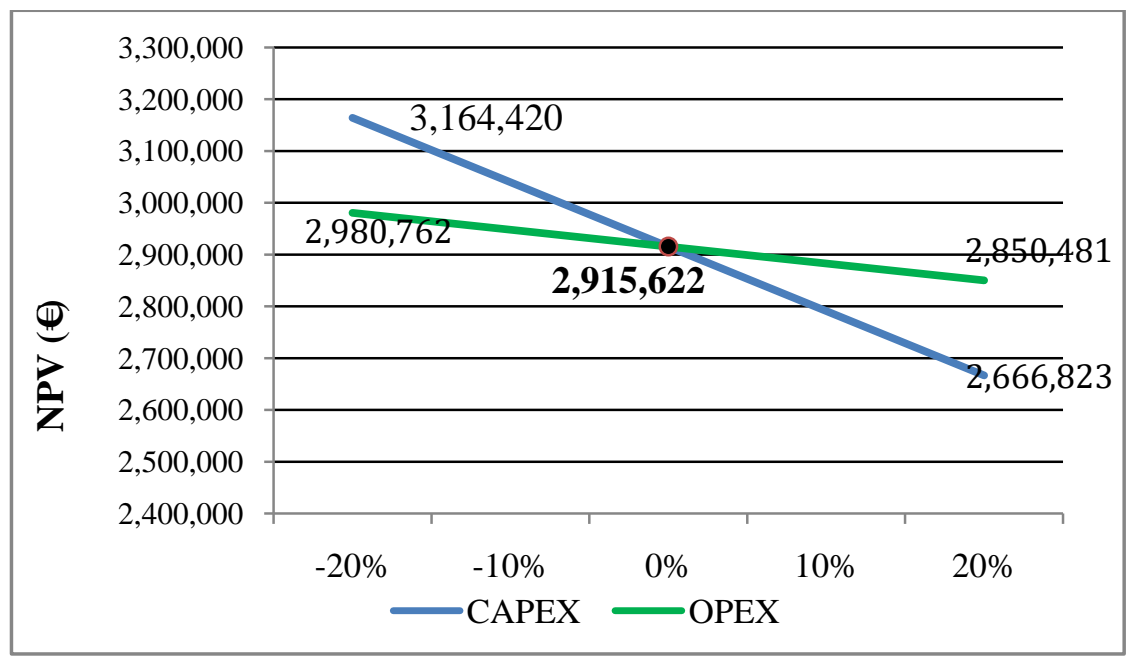

Figure 3. Project sensitivity analysis for Scenario 1.

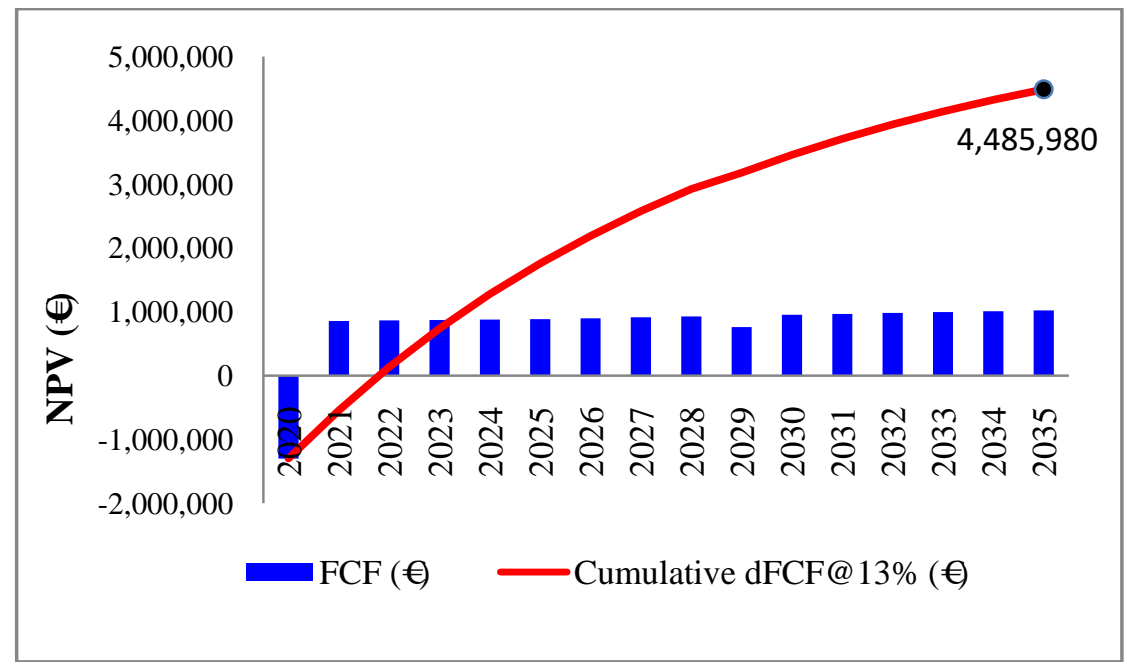

Figure 4. Review of cash flow trends for Scenario 2. 


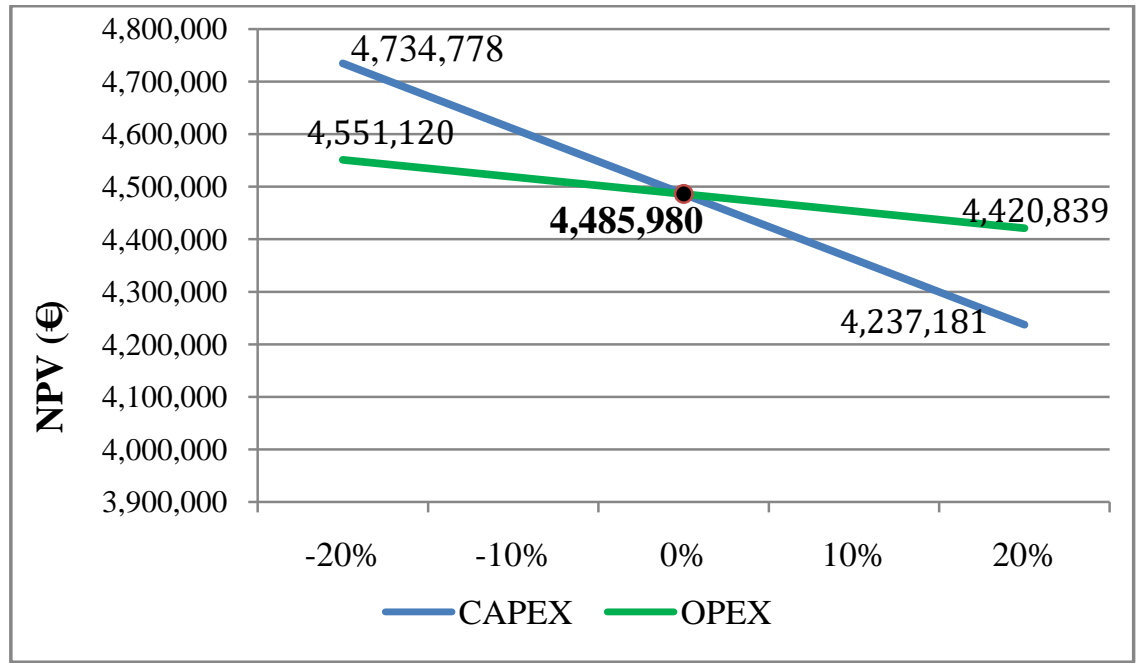

Figure 5. Project sensitivity analysis for Scenario 2

\subsection{Scenario 3-Sale of electricity at free market with using heat for own consumption}

Sale of electricity on the market takes into consideration an average of all traded prices on South East European power exchange (SEEPEX). The authors here use average day-ahead price for Q12021, that is 51.17 €/MWh or $0,051 € / \mathrm{kWh}$ [22]. Based on experience, the average annual growth rate of electricity price of $3 \%$ is adopted and in this analysis it is applied as of 2022. Realization of the revenues founded on the given calculation of electricity market price gives the data shown in Figure 6. The payback period is 20.84 years, which is significantly longer than in the analysis of electricity sale at feed-in tariff. Sensitivity analysis depicted in Figure 7 represents small deviations of CAPEX.

\subsection{Scenario 4-Sale of electricity at free market with supply of heat to third parties}

In this scenario, the authors use certain indicators from the previous scenarios. The application of heat price determined by the analysis of Scenario 2, with applying the price of electricity determined by analyzing Scenario 3, gives the calculation of revenues with the payback period in 4.04 years, as presented in Figure 8. Sensitivity analysis depicted in Figure 9 represents insignificant deviations, without major impact on the project's cost-effectiveness.

\subsection{Scenario 5-Economic analysis with gas procurement}

In order to present a greater insight in return on investments for companies that need to buy gas for their production in CHP plants, the authors have adopted the price of gas for public supply set by the Srbijagas ltd (Gas Industry of Serbia) which is in the range of 29.58 to $32.28 \mathrm{RSD} / \mathrm{m}^{3}$ depending on the category of consumption [23]. For the purpose of this calculation it is taken the middle exchange rate of 125 RSD for 1 EUR, and the price of 31.25 $\mathrm{RSD} / \mathrm{m}^{3}$ gives the price of $0.25 \mathrm{EUR} / \mathrm{m}^{3}$ for gas. Figures 10 and 11 present payback period od 6.48 years.

\subsection{Scenario 6- $\mathrm{CO}_{2}$ emissions avoidance}

This Section investigates the environmental performance of the proposed investment plan, in terms of $\mathrm{CO}_{2}$ emissions savings of $\mathrm{kgCO}_{2}$ emitted on an annual basis. Base Case is the case reflecting the operation of the proposed CHP unit and leads to almost 4.000 tones $\mathrm{CO}_{2}$ in the atmosphere at an annual level. Figure 12 shows $\mathrm{CO}_{2}$ emissions in each Case (tones) and $\mathrm{CO}_{2}$ emissions variation (\%) when compared to the emissions level of the Base Case. In Case 1, representing the case of utilizing a natural gas-fired boiler with a thermal efficiency of $85 \%$ and the current structure and $\mathrm{CO}_{2}$ emissions intensity of the Serbian power system, the $\mathrm{CO}_{2}$ emissions for the same heat and electricity production rise to more than 9.000 tones $\mathrm{CO}_{2}$, and thus they record an increase of around $128 \%$ when compared to the corresponding emissions of the Base Case (or the emissions of the Base Case are decreased by $56 \%$ in comparison with the ones of Case 1). In Case 2, it is assumed a small increase in the thermal efficiency of the natural gas-fired boiler (90\%) and the same structure and $\mathrm{CO}_{2}$ emissions intensity of the Serbian power system. The 
results are similar to those of Case 1 , since the emissions of the Base Case are decreased by $55.6 \%$ in comparison to the ones in Case 2. For the remaining cases (Cases 3-10), it is assumed that the thermal efficiency of the natural gas-fired boiler remains constant and equals $90 \%$, while the $\mathrm{CO}_{2}$ emissions intensity of the Serbian power system is decreased by a step of $0.1 \mathrm{kgCO}_{2} / \mathrm{kWh}$, starting from $0.70 \mathrm{kgCO}_{2} / \mathrm{kWh}$ in Case 3 . The results indicate that the installation of a CHP unit constitutes an environmentally friendlier option up to Case 7, when the $\mathrm{CO}_{2}$ emissions intensity of the Serbian power system equals $0.30 \mathrm{kgCO}_{2} / \mathrm{kWh}$. Case 8 , where the $\mathrm{CO}_{2}$ emissions intensity of the Serbian power system equals $0.25 \mathrm{kgCO}_{2} / \mathrm{kWh}$ comprises an equivalent option in terms of the environmental performance with that of the CHP installation. Finally, the last 2 Cases (Cases 9-10), representing a future power system almost fully dominated by renewable energy sources, lead to a less carbon intensive impact, since their $\mathrm{CO}_{2}$ emissions are decreased by $10 \%$ and $30 \%$ respectively, when compared to the corresponding ones of the Base Case.

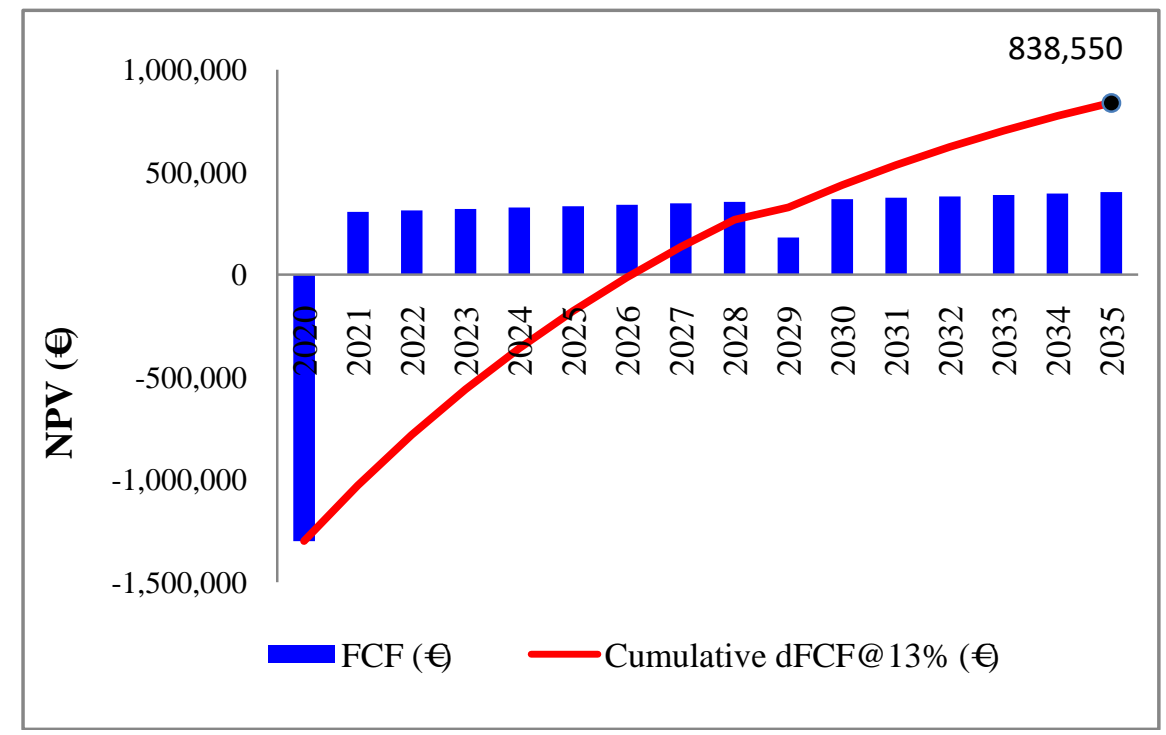

Figure 6. Review of cash flow trends for Scenario 3.

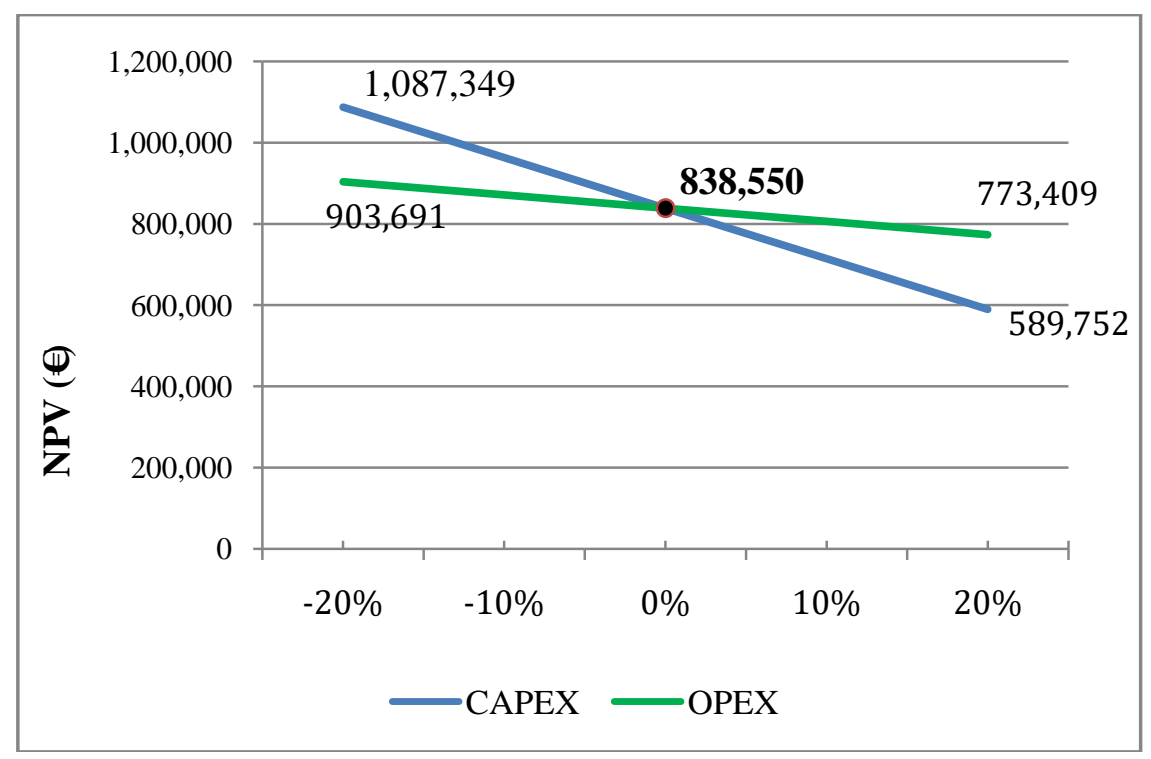

Figure 7. Project sensitivity analysis for Scenario 3. 


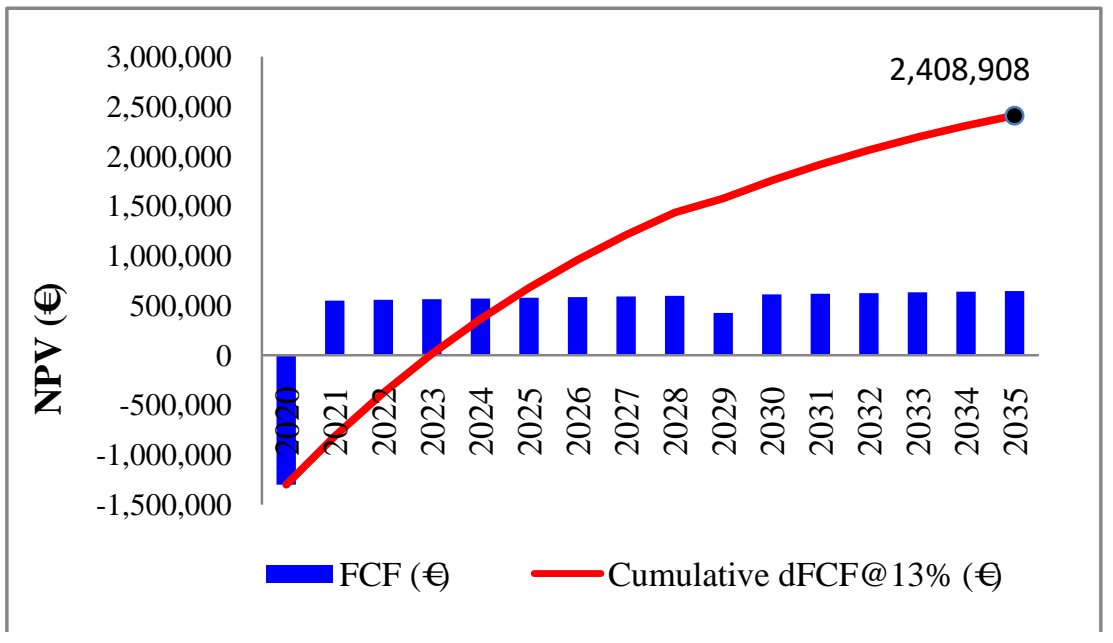

Figure 8. Review of cash flow trends for Scenario 4.

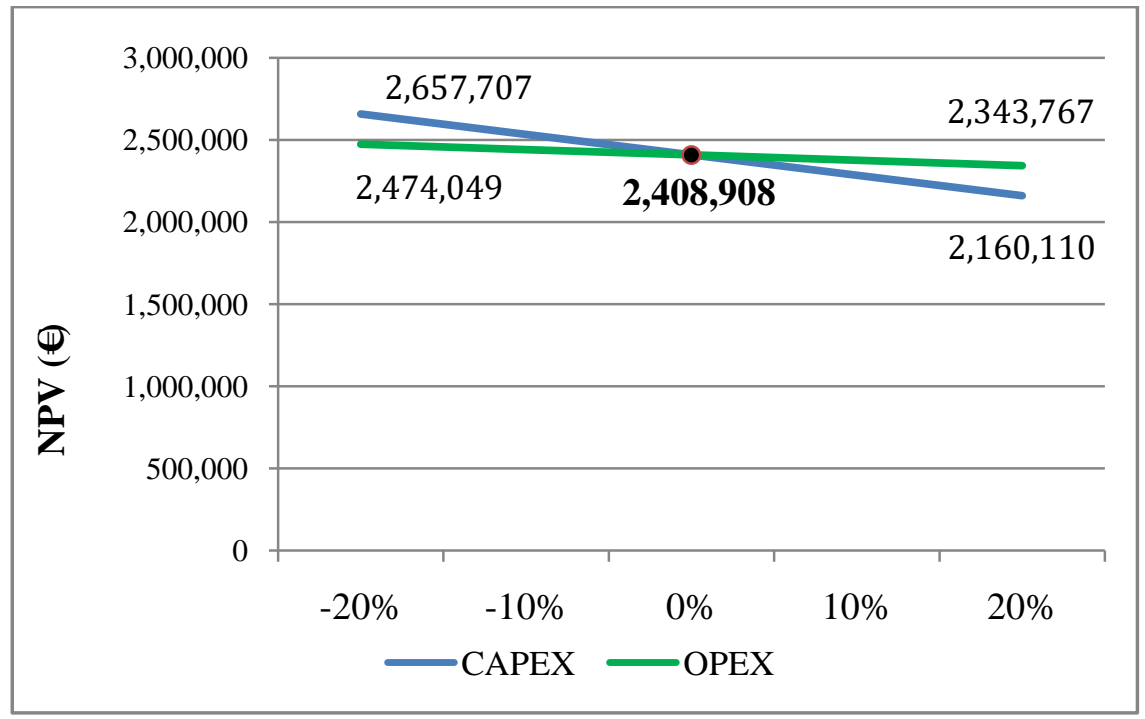

Figure 9. Project sensitivity analysis for Scenario 4.

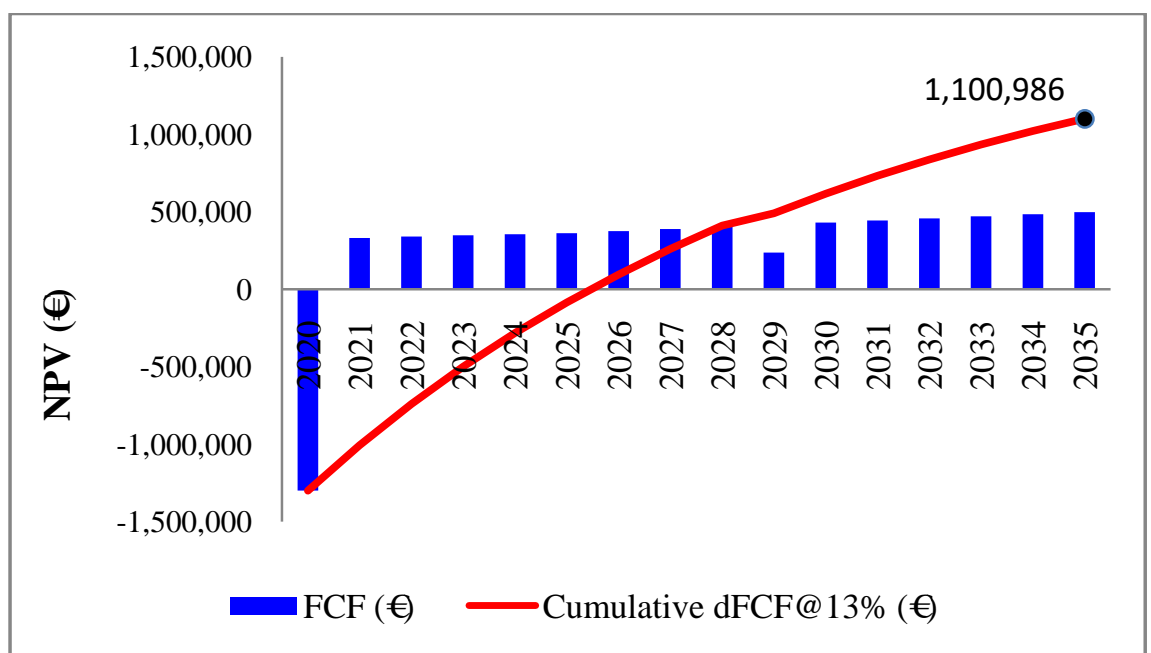

Figure 10. Review of cash flow trends for Scenario 5. 


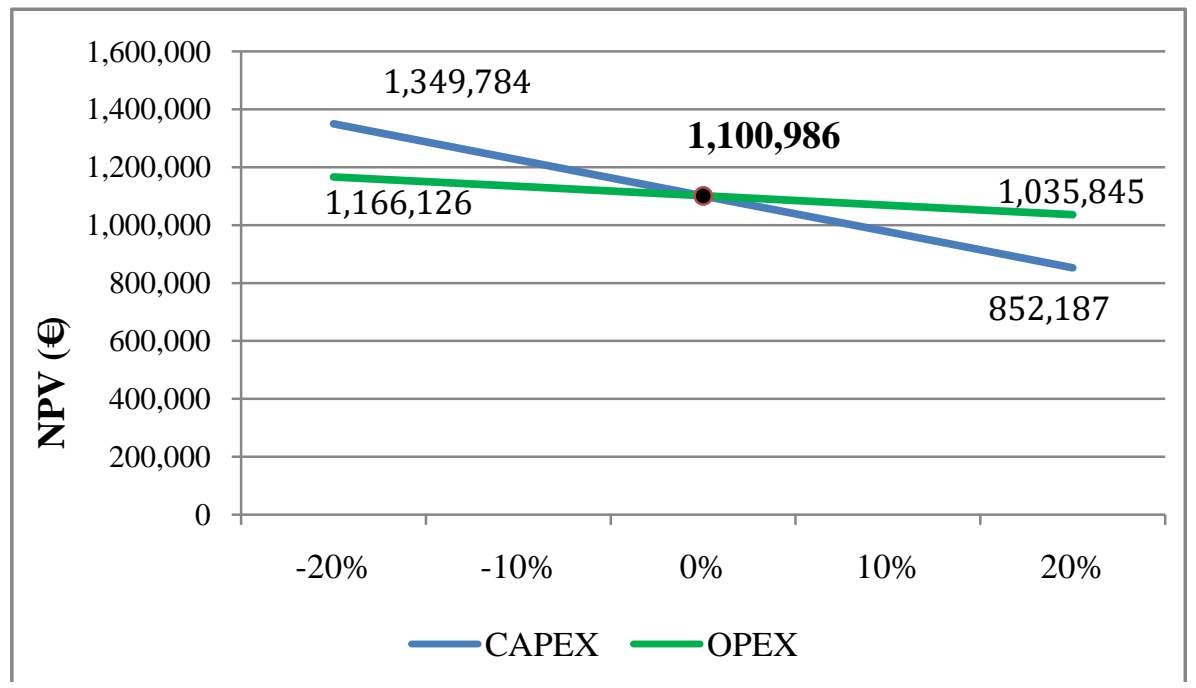

Figure 11. Project sensitivity analysis for Scenario 5.

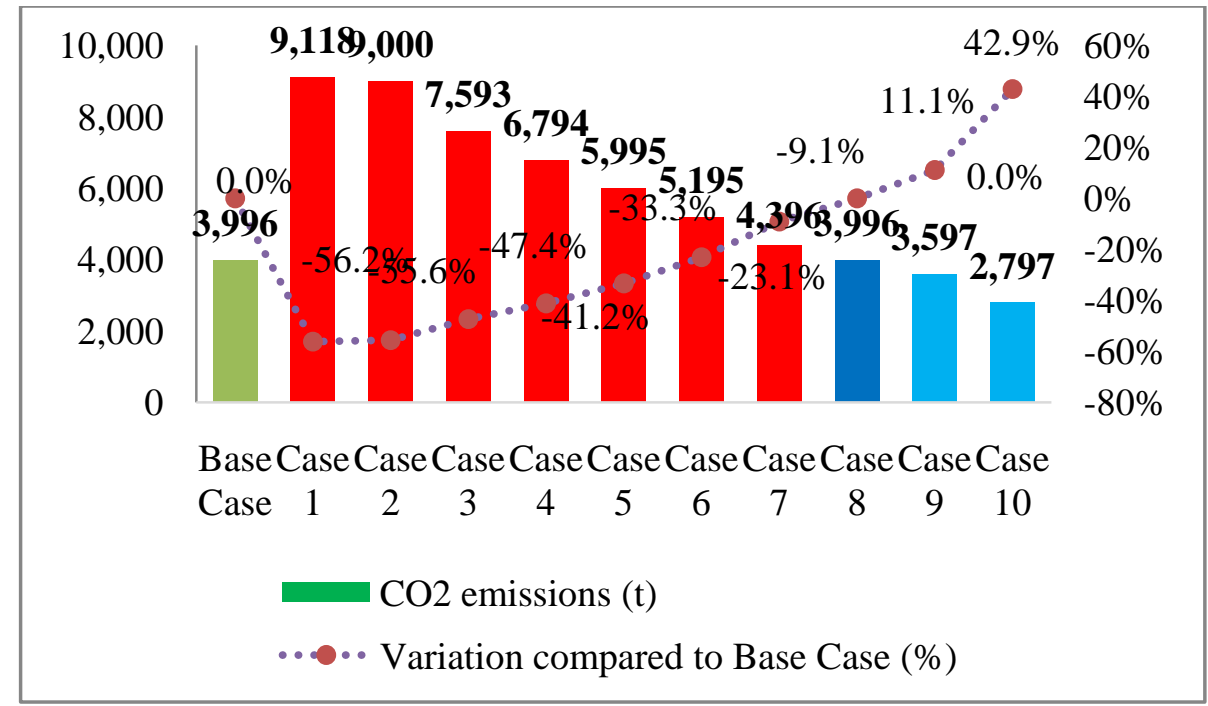

Figure 12. $\mathrm{CO}_{2}$ emissions avoidance.

\section{Results and Discussion}

This paper presented a generic methodological framework for implementing an economic feasibility analysis of installing and utilizing CHP at oil and gas fields. The proposed framework was applied in a real case study of the Serbian energy system. The economic assessment of using NPV and dFCF, in compliance with the regulatory framework, has been carried out on four different scenarios. The paper provides useful insights and it is able to help investors to decide on selecting the most cost-effective scenario.

By determining revenues and expenses based on input data and feed-in tariff data, the authors get information on the indicators presented in Figure 2 which shows that the invested money will be returned in a period of 3.62 years for the given mode of operation. This mode of operation yields revenues through sale of electricity while heat is used for own consumption. From the Project Sensitivity Analysis presented in Figure 3, it can be concluded that deviations in capital and operating expenses in the given percentage, compared to the initial assumptions, do not weigh on the project's cost-effectiveness significantly. On the other hand, sale of electricity at feed-in tariff with supply of heat to the third parties ensures additional revenue and shortens the return on investment period, which is 2.80 years, as shown in Figure 4. Sensitivity analysis depicted in Figure 5 represents small deviations, considering the total amount of NPV, which can have minor impact on the project's cost-effectiveness. Realization of the 
revenues founded on the given calculation of electricity market price gives the data shown in Figure 6 . The payback period is 20.84 years, which is significantly longer than in the analysis of electricity sale at feed-in tariff. Sensitivity analysis depicted in Figure 7 represents small deviations of CAPEX, which do not have major impact on the project's cost-effectiveness. The application of heat price determined by the analysis of scenario 2, with applying the price of electricity determined by analyzing scenario 3, gives the calculation of revenues with the payback period in 4.04 years, as presented in Figure 8. Sensitivity analysis depicted in Figure 9 represents insignificant deviations, without major impact on the project's cost-effectiveness. Economic analysis with gas procurement presented in Figure 10 prove return on investments in 6.48 years with insignificant impact of costs deviations to the project, shown in Figure 11.

According to the preformed calculations for four scenarios, it was demonstrated that electricity sales at feed-in tariff and sale of heat to the third parties is the most cost-effective scenario because of the shortest payback period. Scenario with sale of electricity at free market and using heat for own consumption, appeared to be the least cost-effective scenario with the longest payback period.

\section{Conclusion}

On the basis of the previous discussion, it can be concluded that economic assessment of implementing combined heat and power plants at oil and gas fields, implies that these plants are cost-efficient. Firstly, all examined scenarios proved to have positive income on investment in certain time, even scenario with gas procurement. Secondly, sale of electricity at feed-in tariff with sale of heat to the third parties appears to have the shortest payback period. According to the case study of Serbia, this paper contributes to the literature by shedding a new light on question whether combined heat and power plants are cost-effective if they are built at oil and gas fields. This is very important from both environmental and economical point of view. Further studies are required to enable formulation how to develop a detailed mathematical model for the design and operational planning of the distribution grid considering economic, technical and environmental aspects, electric vehicles' penetration, as well as the availability of a variety of possible candidate technologies and different scales of energy demand to be satisfied.

\section{References}

[1] T. Lieuwen, V. Yang, and R. Yetter. (2010). Synthesis gas combustion: Fundamentals and Applications, United States, Taylor \& Francis Group, CRC Press, 2010.

[2] CHP unit installation project, equipment specification,_-technical documentation. Internal company report, pp. 1-23, 2015.

[3] Serbian Ministry of Energy, Development and Environmental Protection. Republic of Serbia: Decree on Incentives for Privileged Power Producers, Official gazette RS, No 8. Belgrade, 2013.

[4] D. D. Gvozdenacand T. S. Simić. (2012). “About the Serbian energy efficiency problems”, Thermal Science, vol. 9 (suppl. 1), pp. 1-5, 2012, doi: http://dx.doi.org/10.2298/TSCI120205056G.

[5] B. Stojčetović, Dj. Nikolić, V. Velinov, and D. Bogdanović. (2016). “Application of integrated strengths, weaknesses, opportunities, and threats and analytic hierarchy process methodology to renewable energy project selection in Serbia”, Journal of Renewable and Sustainable Energy, vol. 8, no. 035906, 2016, doi: http://dx.doi.org/10.1063/1.4950950.

[6] V. Rajović, F. Kiss, N. Maravić, and O. Bera. (2016). "Environmental flows and life cycle assessment of associated petroleum gas utilization via combined heat and power plants and heat boilers at oil fields”, Energy Conversion and Management, vol. 118, pp. 96-104, 2016, doi: http://dx.doi.org/10.1016/j.enconman.2016.03.084.

[7] A. Colmenar-Santos, E. Rosales-Asensio, D. Borge-Diez, and J. J. Blanes-Peiro. (2016). "District heating and cogeneration in the EU-28: Current situation, potential and proposed energy strategy for its generalisation”, Renewable and Sustainable Energy Reviews, vol. 62, pp. 621-639, 2016, doi: http://dx.doi.org/10.1016/j.rser.2016.05.004.

[8] J. Y. Kang, D. W. Kang, T. S. Kim, and K. B. Hur. (2014). "Economic evaluation of biogas and natural gas co-firing in gas turbine combined heat and power systems”, Applied Thermal Engineering, vol. 70, no. 1, pp. 723-731, 2014, doi: 10.1016/j.applthermaleng.2014.05.085.

[9] H. R. Sadeghian and M. M. Ardehali. (2016). “A novel approach for optimal economic dispatch scheduling of integrated combined heat and power systems for maximum economic profit and minimum environmental emissions based on Benders decomposition”, Energy, vol. 102, pp. 10-23, 2016, doi: http://dx.doi.org/10.1016/j.energy.2016.02.044.

[10] R. E. Klaassen and M. K. Patel. (2013). "District heating in the Netherlands today: A techno-economic assessment for NGCC-CHP (Natural Gas Combined Cycle combined heat and power)”, Energy, vol. 54, pp. 63-73, 2013, doi: http://dx.doi.org/10.1016/j.energy.2013.02.034. 
[11] J. L. Mojica, D. Patersen, B. Hansen, K. M. Powell, and J. D. Hedengren. (2017). “Optimal combined long-term facility design and short-term operational strategy for CHP capacity investments”, Energy, vol. 118, pp. 97-115, 2017, doi: http://dx.doi.org/10.1016/j.energy.2016.12.009.

[12] K. Amirnekooei, M. M. Ardehali, and A. Sadri. (2017). "Optimal energy pricing for integrated natural gas and electric power network with considerations for techno-economic constraints”, Energy, vol. 123, pp. 693-709, 2017, doi: 10.1016/j.energy.2017.01.145.

[13] N. E. Koltsaklis, G. M. Kopanos, and M. C. Georgiadis. (2014). "Design and Operational Planning of Energy Networks Based on Combined Heat and Power Units”, Industrial \& Engineering Chemistry Research, vol. 53, no. 44, pp. 16905-16923, 2014, doi: http://dx.doi.org/10.1021/ie404165c.

[14] Serbian Ministry of Energy, Development and Environmental Protection, Republic of Serbia: Decree on Incentives for Production of Electricity from Renewable Energy Sources and High-efficiency Combined Production of Electricity and Thermal Energy. Official gazette RS 56, 2016, Belgrade.

[15] M. Jansen. (1986). “Agency costs of free cash flow, corporate finance, and takeovers”, The American Economic Review, Vol. 76, No. 2, pp. 323-329, 1986.

[16] R. E. Shrieves and J. M. Wachowicz. (2001). "Free cash flow (FCF), economic value added (EVA ${ }^{\mathrm{TM}}$ ), and net present value (NPV): A reconciliation of variations of discounted-cash-flow (DCF) valuation”, The Engineering Economist, vol. 46, no. 1, pp. 33-52, 2001, doi: http://dx.doi.org/10.1080/00137910108967561.

[17] S. G. Bennet. (1991). The quest for value: The EVA management guide, New York, Harper Business, 1991.

[18] C. T. Tsao. (2012). “Fuzzy net present values for capital investments in an uncertain environment”, Computers \& Operations Research, vol. 39, no. 8, pp. 1885-1892, 2012, doi: https://doi.org/10.1016/j.cor.2011.07.015.

[19] M. Ehrhardt and E. Brigham. (2011). Financial Management: Theory and Practice, United States of America: South-Western Cengage Learning, 2011.

[20] S. D. Promislow and D. Spring. (1996). "Postulates for the internal rate of return of an investment project", Journal of Mathematical Economics, vol. 26, no. 3, pp. 325-361, 1996, doi: http://dx.doi.org/10.1016/0304-4068(95)00747-4.

[21] R. I. Reul. (1957). “Profitability index for investments”, Harvard Business Review, vol. 35, no. 4, pp. 116-132, 1957.

[22] SEEPEX - Serbian power exchange, Day-ahead electricity price, [Online]. Available: http://seepex-spot.rs/sr/download/Activity\%20Reports. [Accessed: 04-February-2020].

[23] Srbijagas. Price of the gas, Available: http://www.srbijagas.co.rs/naslovna.1.html. [Accessed 10.03.17]. 